J. A. MCINTOSH*, T. BENKOVICS, S. M. SILVERMAN, M. A. HUFFMAN, J. KONG,

P. E. MALIGRES, T. ITOH, H. YANG, D. VERMA, W. PAN, H. HO, J. VROOM, A. M. KNIGHT,

J. A. HURTAK, A. KLAPARS, A. FRYSZKOWSKA, W. J. MORRIS, N. A. STROTMAN,

G. S. MURPHY, K. M. MALONEY, P. S. FIER* (MERCK \& CO., INC., RAHAWAY, USA)

Engineered Ribosyl-1-kinase Enables Concise Synthesis of Molnupiravir, an Antiviral for COVID-19

ACS Cent. Sci. 2021, DOI: 10.1021/acscentsci.1c00608.

\section{Efficient Synthesis of Molnupiravir by a Biocatalytic Cascade Involving a Phosphate-Recycling Strategy}

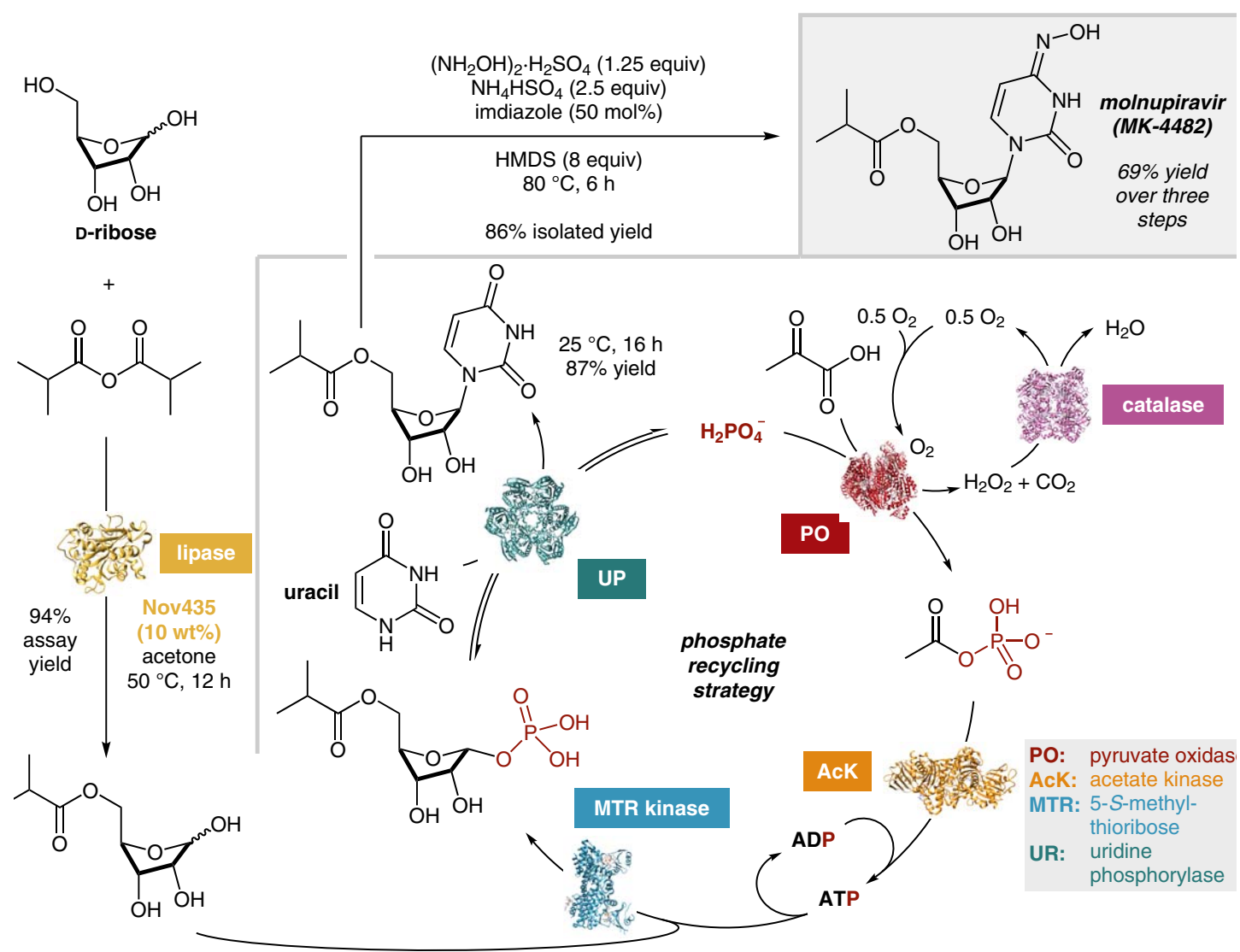

Significance: Fier, Mclntosh, and co-workers disclose a highly efficient enzymatic cascade approach to the experimental COVID-19 antiviral agent monupiravir (Lagevrio; MK-4482). The route features an unprecedented biocatalytic nucleoside synthesis with a 5-esterified sugar and a novel phosphate-recycling strategy that obviates the need for a stoichiometric phosphoryl donor and separate removal of inorganic phosphate. Conversion of the amidic carbonyl into the required oxime proceeds efficiently in neat hexamethyldisilazane (HMDS) as a mild dehydrating agent to furnish molnupiravir in $69 \%$ yield over three steps.
Comment: The developed three-step synthesis of molnupiravir represents a vast improvement on the initial ten-step route which gave less than $10 \%$ overall yield. Key to the success of the biocatalytic cascade approach was the use of specifically evolved ribosyl-1-kinase and uridine phosphorylase enzymes in conjunction with an efficient phosphate-recycling strategy. A practical benefit of the in situ silylation in the last step is the convenient removal of inorganic salts. The new biocatalytic approach is expected to serve as a general tool for the rapid synthesis of nucleosides.

\section{Category}

Organo- and

Biocatalysis

Key words

molnupiravir

enzymatic cascade

ribosyl kinase

phosphate recycling medicinal chemistry antivirals

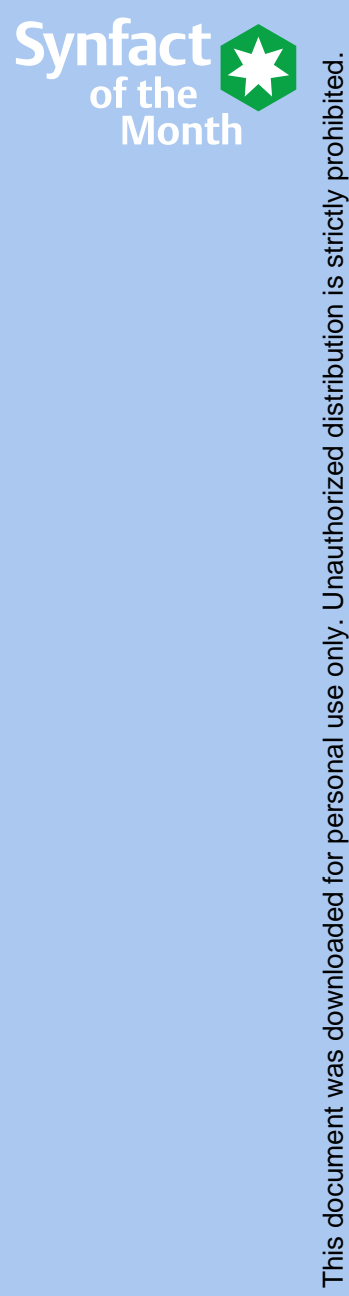

